\title{
Ultra-radical surgery for advanced ovarian cancer- a retrospective cohort study in a tertiary referral cancer center in the UK
}

\section{Konstantinos Palaiologos ( $\nabla$ kostas_pal8@hotmail.com )}

Department of Obstetrics and Gynecology, Hull Royal Infirmary Hospital, Hull University Teaching Hospitals NHS Trust, Hull, UK https://orcid.org/0000-0002-0059-6532

\section{Zoe Nikoloudaki}

Department of Obstetrics and Gynecology, Hull Royal Infirmary Hospital, Hull University Teaching Hospitals NHS Trust, Hull, UK

\section{Tolu Adedipe}

Department of Obstetrics and Gynecology, Hull Royal Infirmary Hospital, Hull University Teaching Hospitals NHS Trust, Hull, UK

\section{Susanne Booth}

Department of Obstetrics and Gynecology, Hull Royal Infirmary Hospital, Hull University Teaching Hospitals NHS Trust, Hull, UK

\section{Marina Flynn}

Department of Obstetrics and Gynecology, Hull Royal Infirmary Hospital, Hull University Teaching Hospitals NHS Trust, Hull, UK

\section{Pavlos Lykoudis}

Department of Obstetrics and Gynecology, Hull Royal Infirmary Hospital, Hull University Teaching Hospitals NHS Trust, Hull, UK

\section{Theodoros Giannopoulos}

Department of Obstetrics and Gynecology, Hull Royal Infirmary Hospital, Hull University Teaching Hospitals NHS Trust, Hull, UK

\section{Research Article}

Keywords: advanced ovarian cancer, ultra-radical surgery, survival rate

Posted Date: February 24th, 2022

DOI: https://doi.org/10.21203/rs.3.rs-1329637/v1

License: (a) (i) This work is licensed under a Creative Commons Attribution 4.0 International License. Read Full License 


\section{Abstract \\ Background}

Ovarian cancer is the leading cause of death from gynaecological cancer in the UK. The standard of care is a combination of surgery and chemotherapy. The aim of the treatment is the resection of all macroscopic disease. In selected cases of advanced ovarian cancer this is achieved with ultra-radical surgery. However, NICE encourages further research due to low quality evidence on the safety and efficacy of this extensive surgery.

\section{Objective}

The aim of this study is to examine the morbidity and survival rates of ultra-radical surgery for advanced ovarian cancer performed in our unit and compare our findings with the current literature.

\section{Methods}

This is a retrospective study of 39 patients diagnosed with stage IIIA-IV ovarian and primary peritoneal cancer who underwent surgery in our unit between 2012 and 2020. The main outcome measures were the perioperative complications, the disease-free survival, the overall survival rate and the recurrence rate.

\section{Results}

The study enrolled 39 patients with stages IIIA-IV who were treated in our unit between 2012 and 2020. 21 patients were at stage III (53.8\%) whereas $18(46.1 \%)$ at stage IV. 14 patients underwent primary and 25 secondary debulking surgery. Major and minor complications occurred $17.9 \%$ and $56.4 \%$ of the patients, respectively. Complete cytoreduction following surgery was achieved in 24 cases (61.5\%). The mean and the median survival time were 4.8 years and 5 years, respectively. The mean disease free survival time was 2.9 years while median disease free survival time was 2 years. Age $(p=0.028)$ and complete cytoreduction $(p=0.048)$ were found to be significantly associated with survival. Primary debulking surgery was significantly associated with lower probability of recurrence $(p=0.049)$.

\section{Conclusion}

Although the number of patients is relatively small, our study indicates that ultra-radical surgery in centres with high expertise may result in excellent survival rates with an acceptable rate of major complications. All patients in our cohort were operated by an accredited Gynaecological Oncologist and a Hepatobiliary General Surgeon with a special interest in ovarian cancer. A few cases required input from a Colorectal and a Thoracic Surgeon. We believe that the careful selection of the patients that can benefit from ultra-radical surgery and our model of joint surgery can explain our excellent results. Further research is essential to 
establish that ultra- radical surgery has an acceptable rate of morbidity for patients with advanced ovarian cancer.

\section{Introduction}

Ovarian cancer is the 7th most common cancer and 8th most common cause of death from cancer in women worldwide. This type of cancer remains the most lethal one and is often referred to as the silent killer. One of the main reasons is that the diagnosis is established at a late stage, usually stage III. The treatment of advanced ovarian cancer includes a combination of debulking surgery and chemotherapy. Debulking surgery also known as cytoreductive surgery is a multi-visceral operation aiming at the complete resection of all visible disease. It is well established that the amount of residual disease after surgery is the most important prognostic factor of survival.

The management of advanced ovarian cancer requires a multidisciplinary approach. There has been a heated debate and controversy until now regarding primary debulking surgery versus neoadjuvant chemotherapy plus internal debulking surgery. In advanced stages of the disease, extensive surgery might be required in the form of ultra-radical surgery. The current evidence of the safety and efficacy of ultraradical surgery is insufficient. Hence, the National Institute for Health and Care Excellence (NICE) recommends that this procedure should not be done except with special arrangements of clinical governance, consent, audit and research.

This study examines the complications, the recurrence and the survival rate in a series of cases with advanced ovarian cancer that were treated with ultra-radical surgery either in the form of primary or interval debulking surgery in a tertiary center in the UK.

\section{Methods}

Definition of the procedure as per NICE: Extensive or ultra-radical surgery for advanced ovarian cancer is a development and extension of standard (radical) surgery. The precise differences between these procedures are not well defined, but some typical features of ultra-radical surgery include:

- Stripping of the diaphragm

- Extensive stripping of the peritoneum

- Multiple resection of the bowel (excluding localized colonic resection)

- Liver resection

- Partial gastrectomy

- Cholecystectomy

- Splenectomy

The aim of ultra-radical surgery is to resect all visible disease. Complete cytoreduction is defined as resection of all macroscopic disease, while suboptimal is having residual disease of more than $1 \mathrm{~cm}$. 
Inclusion criteria:

1. Patients with stage IIIA and above with ovarian or primary peritoneal cancer

2. Patients who had ultra-radical surgery meeting the criteria described above either in the form of primary or interval debulking surgery

The patients who had ultra-radical surgery for recurrent disease and those who were found to have earlystage disease following histology results were excluded.

All patients were followed from the day of their treatment until November 2021, or until death.

Complications were grouped as minor (I-II) and major (III-V) as per the Clavien Dindo Classification of Surgical Complications.

A systematic review was performed utilizing the local database of the gynaecological oncology department of Hull University Teaching Hospitals NHS Trust between the years 2012 and 2020. 39 patients met the inclusion criteria. 2 patients were found to have early stage disease following histology, and hence were excluded from the survival and recurrence rate calculations. The project was registered to the audit and research department with the license number 2021.137. Consent was not required since no patient's identifiable data was used. The confidentiality and privacy of the patients was maintained through anonymization. The required information was retrieved from the archived personal medical documents and the electronic medical records in the hospital's software (LORENZO).

\section{Statistical analysis}

The quantitative variables were expressed as mean (Standard Deviation) or as median (interquartile range). The qualitative variables were expressed as absolute and relative frequencies. The Kaplan - Meier survival estimates for surviving and recurrence were graphed over the follow-up period. Life table analyses were used to calculate the cumulative survival rate (standard errors) for specific time intervals. The prognostic value of each variable was first assessed by the univariate Cox regression analysis. The variables that showed significant association with the outcome were included in the multivariate Cox proportional-hazard model in a stepwise method ( $p$ for entry $0.05, p$ for removal 0.10 ) to determine the independent predictors for the overall survival and the recurrence. The assumption of proportional hazards was evaluated by testing for interaction with a continuous time variable. The hazard ratios (HR) with $95 \%$ confidence intervals $(95 \% \mathrm{Cl})$ were computed from the Cox regression analyses. All reported $\mathrm{p}$ values are two-tailed. The statistical significance was set at $p<0.05$ and analyses were conducted using SPSS statistical software (version 22.0).

\section{Results}

39 women were included in the study. The mean age was 61.9 years ( $S D=10.3$ years). 21 patients were at stage III (53.8\%) and $18(46.1 \%)$ at stage IV. 14 patients (35.9\%) had primary while $25(64.1 \%)$ had interval debulking surgery. 
There were no perioperative deaths.

Intraoperatively, 3 patients required blood transfusion and one patient had bladder injury repair. Furthermore, $7(17.9 \%)$ and $22(56.4 \%)$ of the patients had major and minor complications, respectively. 1 patient developed pneumothorax and was intubated and returned to the intensive care unit. 4 patients returned to theater; three of them due to superficial wound dehiscence. One patient had signs of perforation on the post op CT scan which were not confirmed at an exploratory laparotomy, so only peritoneal lavage was required.

Two patients developed intra-abdominal collections that were drained radiologically.

The minor complications are described on Figure 3.

Complete resection of the disease was achieved in 24 patients (61.5\%). The median duration of hospitalization was 8 days (IQR: 6-11 days). For 34 patients there was no delay to chemotherapy.

The mean survival time was 4.8 years ( $\mathrm{SE}=0.5$ years) and the median survival time was 5 years. The patients' survival curve according to the Kaplan-Meier method is presented in Figure 1 . The probability of surviving at 6 months and at one year was $97.4 \%$ (SE=2.6\%), while at 3, 5 and 7 years it was $67 \%(\mathrm{SE}=7.8 \%$ ), $51.4 \%(8.6 \%)$ and $37.4 \%(\mathrm{SE}=9.3 \%)$ respectively.

The mean disease free survival time was 2.9 years ( $\mathrm{SE}=0.4$ years) and the median disease free survival time was 2 years. The patients' disease free survival curve according to the Kaplan-Meier method is presented in Figure 2. The probability of not having a recurrence at 6 months and at one year was $96.6 \%(\mathrm{SE}=3.4 \%)$, while at 3,5 and 7 years it was $39.6 \%(\mathrm{SE}=9.2 \%), 23.6 \%(8.4 \%)$ and $11.8 \%(\mathrm{SE}=7.2 \%)$ respectively.

The patients who underwent primary surgery had $59 \%$ lower probability of recurrence compared to those who underwent interval debulking surgery (Table 2). When multiple Cox regression was conducted, the type of surgery (primary vs interval) was found as the only factor to be significantly associated with recurrence, in a similar way to the univariate analysis.

Older age was significantly associated with greater hazard (Table 3). Also, the cases that had suboptimal cytoreduction had 2.32 times greater hazard compared to complete cytoreduction. Moreover, prolonged hospitalization was significantly associated with greater hazard. When multiple Cox regression was conducted, the age and complete/optimal cytoreduction were found to be significantly associated with survival (Table 4). 
Table 1

Sample characteristics

\begin{tabular}{|c|c|}
\hline & $\mathbf{N}(\%)$ \\
\hline Age, mean (SD) & $61.9(10.3)$ \\
\hline \multicolumn{2}{|l|}{ Stage } \\
\hline IIIA & $3(7.8)$ \\
\hline IIIB & $1(2.6)$ \\
\hline IIIC & $17(43.6)$ \\
\hline IVA & $14(35.9)$ \\
\hline IVB & $4(10.3)$ \\
\hline \multicolumn{2}{|l|}{ Surgery } \\
\hline Interval & $25(64.1)$ \\
\hline Primary & $14(35.9)$ \\
\hline \multicolumn{2}{|l|}{ Lymphadenectomy } \\
\hline No & $32(82.1)$ \\
\hline Yes, negative & $5(12.8)$ \\
\hline Yes, positive & $2(5.1)$ \\
\hline Intra-operative complications & $4(10.3)$ \\
\hline Major complications & $7(17.9)$ \\
\hline Minor complications & $22(56.4)$ \\
\hline \multicolumn{2}{|l|}{ Cytoreduction } \\
\hline Complete & $24(61.5)$ \\
\hline Suboptimal & $15(38.5)$ \\
\hline Length of stay (days), median (IQR) & $8(6-11)$ \\
\hline \multicolumn{2}{|l|}{ Time to Chemotherapy } \\
\hline No delay & $34(87.2)$ \\
\hline Delay & $3(7.7)$ \\
\hline Canceled & $2(5.1)$ \\
\hline \multicolumn{2}{|l|}{ Anesthesia } \\
\hline Epidural & $7(18.9)$ \\
\hline
\end{tabular}




\begin{tabular}{|ll|}
\hline & $\mathbf{N}(\%)$ \\
\hline \multicolumn{1}{|c|}{ Spinal } & $12(32.4)$ \\
Death & $23(59.0)$ \\
Recurrence & $23(79.3)$ \\
\hline
\end{tabular}


Table 2

Patients' percentages of recurrence associated with their characteristics and results from univariate Cox analysis

\begin{tabular}{|c|c|c|c|c|c|}
\hline & & Recurrenc & & $\mathrm{HR}(95 \% \mathrm{Cl})+$ & $\mathbf{P}$ \\
\hline & & No & Yes & & \\
\hline & & $\mathbf{N}(\%)$ & $N(\%)$ & & \\
\hline Age, mean (SD) & & $\begin{array}{l}57.7 \\
(13.7)\end{array}$ & $\begin{array}{l}61.3 \\
(9.2)\end{array}$ & $\begin{array}{l}1.02(0.98- \\
1.07)\end{array}$ & 0.237 \\
\hline Stage & III & $3(18.8)$ & $13(81.3)$ & reference & \\
\hline & IV & $3(23.1)$ & $10(76.9)$ & $\begin{array}{l}0.96(0.42- \\
2.21)\end{array}$ & 0.920 \\
\hline Surgery & Interval & $2(11.1)$ & $16(88.9)$ & reference & \\
\hline & Primary & $4(36.4)$ & $7(63.6)$ & $\begin{array}{l}0.41(0.17- \\
0.99)\end{array}$ & 0.049 \\
\hline Lymphadenectomy & No & $4(17.4)$ & $19(82.6)$ & reference & \\
\hline & Yes & $2(33.3)$ & $4(66.7)$ & $\begin{array}{l}0.74(0.25- \\
2.19)\end{array}$ & 0.592 \\
\hline Intra-operative & No & $6(23.1)$ & $20(76.9)$ & reference & \\
\hline & Yes & $0(0.0)$ & $3(100.0)$ & $1.52(0.45-5.2)$ & 0.501 \\
\hline Major complications & No & $5(20.8)$ & $19(79.2)$ & reference & \\
\hline & Yes & $1(20.0)$ & $4(80.0)$ & $\begin{array}{l}0.84(0.28- \\
2.47)\end{array}$ & 0.748 \\
\hline Minor complications & No & $3(25.0)$ & $9(75.0)$ & reference & \\
\hline & Yes & $3(17.6)$ & $14(82.4)$ & $\begin{array}{l}1.23(0.53- \\
2.85)\end{array}$ & 0.632 \\
\hline Cytoreduction & Complete & $5(23.8)$ & $16(76.2)$ & reference & \\
\hline & Suboptimal & $1(12.5)$ & 7 (87.5) & $1.59(0.63-4)$ & 0.326 \\
\hline Length of stay (days), m & (IQR) & $8(6-8)$ & $7(5-9)$ & $\begin{array}{l}1.02(0.97- \\
1.08)\end{array}$ & 0.338 \\
\hline Time to Chemotherapy & No delay & $6(22.2)$ & $21(77.8)$ & reference & \\
\hline & $\begin{array}{l}\text { Delay/ } \\
\text { Canceled }\end{array}$ & $0(0.0)$ & $2(100.0)$ & $\begin{array}{l}1.01(0.23- \\
4.45)\end{array}$ & 0.986 \\
\hline Anesthesia & & & & reference & \\
\hline
\end{tabular}

+Hazard Ratio (95\% Confidence Interval) 


\begin{tabular}{|c|c|c|c|c|}
\hline & Recurren & & HR $(95 \% \mathrm{Cl})+$ & $\mathbf{P}$ \\
\hline & No & Yes & & \\
\hline & N (\%) & $N(\%)$ & & \\
\hline Epidural & $1(20.0)$ & $4(80.0)$ & $\begin{array}{l}0.91(0.29- \\
2.87)\end{array}$ & 0.877 \\
\hline Spinal & $2(20.0)$ & $8(80.0)$ & $\begin{array}{l}0.95(0.38- \\
2.38)\end{array}$ & 0.919 \\
\hline
\end{tabular}


Table 3

Patients' percentages of death associated with their characteristics and results from univariate Cox analysis

\begin{tabular}{|c|c|c|c|c|c|}
\hline & & Death & & $\mathrm{HR}(95 \% \mathrm{Cl})+$ & $\mathbf{P}$ \\
\hline & & No & Yes & & \\
\hline & & $\mathbf{N}(\%)$ & $\mathbf{N}(\%)$ & & \\
\hline Age, mean (SD) & & $\begin{array}{l}58.6 \\
(12.1)\end{array}$ & $\begin{array}{l}64.3 \\
(8.5)\end{array}$ & $\begin{array}{l}1.05(1.01- \\
1.11)\end{array}$ & 0.050 \\
\hline Stage & III & $7(33.3)$ & $14(66.7)$ & reference & \\
\hline & IV & $9(50.0)$ & $9(50.0)$ & $\begin{array}{l}0.79(0.34- \\
1.82)\end{array}$ & 0.578 \\
\hline Surgery & Interval & $7(28.0)$ & $18(72)$ & reference & \\
\hline & Primary & $9(64.3)$ & $5(35.7)$ & $\begin{array}{l}0.47(0.18- \\
1.28)\end{array}$ & 0.140 \\
\hline Lymphadenectomy & No & $11(34.4)$ & $21(65.6)$ & reference & \\
\hline & Yes & $5(71.4)$ & $2(28.6)$ & $\begin{array}{l}0.48(0.11- \\
2.06)\end{array}$ & 0.325 \\
\hline Intra-operative & No & $15(42.9)$ & $20(57.1)$ & reference & \\
\hline & Yes & $1(25.0)$ & $3(75.0)$ & $\begin{array}{l}0.86(0.25- \\
2.94)\end{array}$ & 0.813 \\
\hline Major complications & No & $13(40.6)$ & $19(59.4)$ & reference & \\
\hline & Yes & $3(42.9)$ & $4(57.1)$ & $\begin{array}{l}1.44(0.49- \\
4.26)\end{array}$ & 0.512 \\
\hline Minor complications & No & $6(35.3)$ & $11(64.7)$ & reference & \\
\hline & Yes & $10(45.5)$ & $12(54.5)$ & $\begin{array}{l}1.26(0.55- \\
2.87)\end{array}$ & 0.582 \\
\hline Cytoreduction & Complete & $11(45.8)$ & $13(54.2)$ & reference & \\
\hline & Suboptimal & $5(33.3)$ & $10(66.7)$ & $\begin{array}{l}2.32(1.01- \\
5.64)\end{array}$ & 0.048 \\
\hline Length of stay (days), & (IQR) & $7(5-8)$ & $\begin{array}{l}8(7- \\
17)\end{array}$ & $\begin{array}{l}1.04(1.02- \\
1.06)\end{array}$ & 0.001 \\
\hline
\end{tabular}

+Hazard Ratio (95\% Confidence Interval) 


\begin{tabular}{|c|c|c|c|c|c|}
\hline & & \multicolumn{2}{|l|}{ Death } & \multirow[t]{3}{*}{$\mathrm{HR}(95 \% \mathrm{Cl})+$} & \multirow[t]{3}{*}{$\mathbf{P}$} \\
\hline & & No & Yes & & \\
\hline & & $N(\%)$ & $\mathbf{N}(\%)$ & & \\
\hline \multirow[t]{2}{*}{ Time to Chemotherapy } & No delay & $15(44.1)$ & $19(55.9)$ & reference & \\
\hline & $\begin{array}{l}\text { Delay/ } \\
\text { Canceled }\end{array}$ & $1(20.0)$ & $4(80.0)$ & $\begin{array}{l}2.24(0.75- \\
6.73)\end{array}$ & 0.151 \\
\hline \multirow[t]{3}{*}{ Anesthesia } & & & & reference & \\
\hline & Epidural & $4(57.1)$ & $3(42.9)$ & $\begin{array}{l}0.48(0.14- \\
1.71)\end{array}$ & 0.257 \\
\hline & Spinal & $5(41.7)$ & $7(58.3)$ & $\begin{array}{l}0.78(0.31- \\
1.97)\end{array}$ & 0.606 \\
\hline
\end{tabular}

Table 4

Multivariable Cox analysis results for overall survival

\begin{tabular}{|c|c|c|c|}
\hline & & $\mathrm{HR}(95 \% \mathrm{Cl})+$ & $\mathbf{P}$ \\
\hline \multicolumn{2}{|l|}{ Age } & $1.06(1.01-1.12)$ & 0.028 \\
\hline \multirow[t]{2}{*}{ Cytoreduction } & Complete & reference & \\
\hline & Suboptimal & $2.49(1.01-6.13)$ & 0.048 \\
\hline
\end{tabular}

\section{Discussion}

While complete surgical resection combined with systemic platinum-based chemotherapy remains the principle of advanced ovarian cancer treatment, the extent and timing of surgical debulking continues to be a matter of debate. However, over the past three decades, one factor has remained unchanged: the volume of residual disease after debulking surgery is a strong prognostic factor in ovarian cancer, reinforcing the importance and relevance of surgical effort in the care of these patients $(1-3)$. Based on this and the fact that the majority of the patients are diagnosed at a late stage of the disease, there is a shift towards advanced extra-pelvic procedures also known as ultra-radical surgery. International bodies in gynaecological oncology have acknowledged the importance of ultra-radical surgery for advanced ovarian cancer with the recommendation that upper abdominal procedures should be included as part of the training curriculum for gynaecology oncology trainees. As a result, the National Institute for Health and Care Excellence (NICE) 
recommends that ultra-radical surgery should be practiced in tertiary centers with relevant expertise and be audited regularly (4).

In our tertiary referral center, ultra-radical surgery has been performed since 2012, with the numbers increasing every year. Between 2012 and 2020, 39 patients who were treated surgically for advanced ovarian cancer met the criteria of having ultra-radical surgery as defined by NICE. It is worth mentioning that during 2020-2021, the number of patients who had radical surgery significantly decreased due to the impact of the COVID-19 pandemic. Every patient referred to our tertiary center is reviewed in the weekly multidisciplinary meeting. Following careful selection of the patients with advanced ovarian cancer who require ultra-radical surgery, they are booked in combined theatre lists with the hepatobiliary/upper gastrointestinal surgeons. The input of upper gastrointestinal surgeons is crucial for cases that require extensive upper abdominal surgery such as liver resection, gastrectomy and splenectomy and this might have contributed to the good intra and postoperative outcomes of this study. Recently, the british gynaecological cancer society (BGCS) and the association of upper surgery of Great Britain (AUGIS) have published a document that highlights the importance of having a multidisciplinary approach with the support of the colorectal, upper gastrointestinal and general surgeons when performing this extensive type of procedures (5).

In our study, primary debulking surgery was found to be significantly associated with $59 \%$ lower probability of recurrence, compared to interval debulking surgery, with no statistical difference in the survival rate. Two randomized phase three trials (EORTC55971 and CHORUS) provide evidence that interval debulking following neoadjuvant chemotherapy is an equal approach to advanced ovarian cancer, although both studies were criticized owing to limitations $(6,7)$. One of the most recent studies worth mentioning is the SCORPION study, a phase 3 randomized clinical trial, which showed that neoadjuvant chemotherapy and primary debulking surgery have the same efficacy when used at their maximal possibilities but the toxicity profile is different (8). The Trial on Radical Upfront Surgery in Advanced Ovarian Cancer (TRUST) will hopefully enlighten the management of patients with advanced ovarian cancer, establish predictive and prognostic biomarkers of operability and survival and prove the superiority of primary surgery over the neoadjuvant chemotherapy plus interval debulking (9).

Regarding survival, the median survival time was 5 years with $51.4 \%$ probability of surviving at 5 years. Comparing this to the Office National Statistics of UK, the survival rates for stage III and IV ovarian cancer are $25 \%$ and $15 \%$, respectively (10). The survival reported in this study is above the national rate which is also highlighted in the Ovarian Cancer Audit Feasibility Pilot in 2020. This pilot demonstrated that Humber, Coast and Vale Cancer Alliances performed well in the survival rates for ovarian cancer between 2013 and 2017 reaching $36.2 \%$ net survival of 5 years which is higher compared to the national standards of $34.7 \%$ in England (11). The two prognostic factors significantly associated with survival were the age and the complete resection of the tumour. The mean age of our sample was 61.9 years old. Complete resection of tumour was achieved in $61.5 \%$ which is higher compared to the $54.1 \%$ of the Norfolk and Norwich Hospital study (12). Similar studies have found that complete resection is significantly associated with increased survival and it is one of the main reasons why the ultra-radical approach has been utilized more and more in recent years (13-17). Incorporating surgery, even for those patients with a greater tumour burden and more 
disseminated disease who may require more complex procedures and more resources in terms of theater time and hospital stay, seems to be associated with a significant prolongation of the patients' overall survival compared with chemotherapy alone (18).

Despite the above, skeptics highlight the increased morbidity rate for these patients following surgical intervention. Our data demonstrated that the major complications were limited, affecting only 7 patients of the sample (17.9\%). 4 of them required surgical intervention and they returned to the theater; 3 patients had wound dehiscence and 1 an exploratory laparotomy and washout. 2 patients had intra-abdominal collection drainage by the Interventional Radiology and 1 patient required chest drain insertion and intubation due to pneumothorax. There was no perioperative death. It is important to mention that these extensive surgeries were performed under the joint care of the gynaecology oncology and upper gastrointestinal surgeon consultants. This is probably the contributing factor that resulted in an acceptable morbidity rate. In ultraradical procedures with extensive disease, involvement of other specialties might limit the surgical time and reduce the morbidity while achieving the best care for the patients.

As a result of the above mentioned morbidity rate, $87.2 \%$ of the patients commenced adjuvant chemotherapy without delay. Moreover, the median duration of hospitalization was only 8 days. The study from Yakup Yalcin et al demonstrated that $22.4 \%$ of the patients with advanced ovarian cancer who underwent extensive upper abdominal surgeries had major complications within 30 days after surgery (19). Furthermore, receipt of chemotherapy was similar among women with and without postoperative complications in the retrospective review by Zhaomin Xu et al (20). However, in the dutch gynaecological oncology audit (DGOA), it was apparent that the higher percentage of complications resulted in a prolonged time to start adjuvant chemotherapy (21). In contrast to this study, the retrospective population-based study in the United States by Joseph A. Dottino et.al, showed that in matched primary and interval cytoreductive surgery cohorts, ultra-radical surgery was associated with the increased likelihood of post-operative complications and use of acute care services. Also, in both primary and interval cytoreductive surgery patients, those who had bowel and upper abdominal procedures had multiple 30-day postoperative complications and higher rates of readmission (22).

\section{Conclusion}

This study indicates that ultra-radical surgery in centers with high expertise may result in excellent survival rates with a low rate of major complications. It also indicates that it is possible to achieve a high percentage of cases with no residual disease post-surgery which is the main prognostic factor associated with survival.

In our center ultra-radical surgery did not lead to increased morbidity and delay of chemotherapy and as it appears to be safe and efficient.

We believe that the main reason for our excellent results is our model of joint operations with other Surgical Colleagues who have a particular interest in the management of advanced Ovarian and primary peritoneal cancer. Further research is required to establish if ultra-radical surgery should become the standard of care for those cases. 


\section{Declarations}

\section{Funding was not required for this study.}

\section{Ethical Approval}

The project was registered to the audit and research department with the license number 2021.137.

\section{Informed Consent}

Consent was not required since no patient's identifiable data was used. The confidentiality and privacy of the patients was maintained through anonymization.

\section{Disclosure of potential conflicts of interest}

The authors state that they have no conflict of interest to declare.

\section{References}

1. Aletti, G., Dowdy, S., Gostout, B., Jones, M., Stanhope, C., Wilson, T., Podratz, K. and Cliby, W., 2006. Aggressive Surgical Effort and Improved Survival in Advanced-Stage Ovarian Cancer. Obstetrics \& Gynecology, 107(1), pp.77-85.

2. Tseng JH, Cowan RA, Zhou Q, lasonos A, Byrne M, Polcino T, Polen-De C, Gardner GJ, Sonoda Y, Zivanovic O, Abu-Rustum NR, Long Roche K, Chi DS., 2018. Continuous improvement in primary Debulking surgery for advanced ovarian cancer: Do increased complete gross resection rates independently lead to increased progression-free and overall survival? Gynecol Oncol, 151(1), pp.24-31.

3. Long Roche, K. and Gardner, G., 2019. State of the science: Evolving role of surgery for the treatment of ovarian cancer. Gynecologic Oncology, 155(1), pp.3-7.

4. Nice.org.uk. 2022. Overview / Ultra-radical (extensive) surgery for advanced ovarian cancer / Guidance / NICE. [online] Available at: <https://www.nice.org.uk/Guidance/IPG470> [Accessed 10 January 2022].

5. Anon, 2021. Governance Models to support patient safety when undergoing maximal effort cytoreductive surgery for advanced ovarian/ fallopian tube / primary peritoneal cancer-a joint statement of ACPGBI, ASGBI, AUGIS and BGCS. Available at: https://www.bgcs.org.uk/wpcontent/uploads/2021/12/Joint-statement-Version-1.9_NJW_final.pdf [Accessed January 10, 2022].

6. Kehoe, S., Hook, J., Nankivell, M., Jayson, G., Kitchener, H., Lopes, T., Luesley, D., Perren, T., Bannoo, S., Mascarenhas, M., Dobbs, S., Essapen, S., Twigg, J., Herod, J., McCluggage, G., Parmar, M. and Swart, A., 2015. Primary chemotherapy versus primary surgery for newly diagnosed advanced ovarian cancer (CHORUS): an open-label, randomized, controlled, non-inferiority trial. The Lancet, 386(9990), pp.249257.

7. Onda, T., Satoh, T., Ogawa, G., Saito, T., Kasamatsu, T., Nakanishi, T., Mizutani, T., Takehara, K., Okamoto, A., Ushijima, K., Kobayashi, H., Kawana, K., Yokota, H., Takano, M., Kanao, H., Watanabe, Y., Yamamoto, K., Yaegashi, N., Kamura, T. and Yoshikawa, H., 2020. Comparison of survival between primary 
debulking surgery and neoadjuvant chemotherapy for stage III/IV ovarian, tubal and peritoneal cancers in phase III randomized trial. European Journal of Cancer, 130, pp.114-125.

8. Fagotti, A., Ferrandina, M., Vizzielli, G., Pasciuto, T., Fanfani, F., Gallotta, V., Margariti, P., Chiantera, V., Costantini, B., Alletti, S., Cosentino, F. and Scambia, G., 2021. Randomized Trial of Primary Debulking Surgery Versus Neoadjuvant Chemotherapy for Advanced Epithelial Ovarian Cancer (SCORPIONNCT01461850). Obstetrical \& Gynecological Survey, 76(2), pp.90-91.

9. Reuss, A., du Bois, A., Harter, P., Fotopoulou, C., Sehouli, J., Aletti, G., Guyon, F., Greggi, S., Mosgaard, B., Reinthaller, A., Hilpert, F., Schade-Brittinger, C., Chi, D. and Mahner, S., 2019. TRUST: Trial of Radical Upfront Surgical Therapy in advanced ovarian cancer (ENGOT ov33/AGO-OVAR OP7). International Journal of Gynecologic Cancer, 29(8), pp.1327-1331.

10. Cancer Research UK. 2020. Ovarian Cancer incidence statistics 2016. [online] Available at: <https://www.cancerresearchuk.org/health-professional/cancer-statistics/incidence> [Accessed 10 January 2022].

11. Royal College of Obstetricians \&amp; Gynaecologists. 2020. Ovarian Cancer Audit Feasibility Pilot on Ovarian Cancer. [online] Available at: <https://www.rcog.org.uk/en/news/rcog-welcomes-audit-reporton-ovarian-cancer/?

_t_ip=40.77.167.54\&_t_hit.id=EPiServer_Templates_RCOG_Models_Pages_NewsArticleType/_b15044151833-40d3-8739-ff46b847ca5f_en> [Accessed 10 January 2022].

12. Turnbull, H., Akrivos, N., Wemyss-Holden, S., Maiya, B., Duncan, T., Nieto, J. and Burbos, N., 2016. The impact of ultra-radical surgery in the management of patients with stage IIIC and IV epithelial ovarian, fallopian tube, and peritoneal cancer. Archives of Gynecology and Obstetrics, 295(3), pp.681-687.

13. Martinez, A., Ngo, C., Leblanc, E., Gouy, S., Luyckx, M., Darai, E., Classe, J., Guyon, F., Pomel, C., Ferron, G., Filleron, T. and Querleu, D., 2016. Surgical Complexity Impact on Survival After Complete Cytoreductive Surgery for Advanced Ovarian Cancer. Annals of Surgical Oncology, 23(8), pp.2515-2521.

14. Dessai, S., Patil, V., Chakraborty, S., Babu, S., Bhattacharjee, A., Nayanar, S., Vikram, S. and Balasubramanian, S., 2016. An audit of cytoreductive surgeries in ovarian cancer from a rural based cancer center. Indian Journal of Cancer, 53(2), p.284.

15. Hernandez-Lopez, L. and Elizalde-Mendez, A., 2020. How far should we go in optimal cytoreductive surgery for ovarian cancer?. Chinese Clinical Oncology, 9(5), pp.70-70.

16. Liberale G, Pop CF, Polastro L, Kerger J, Moreau M, Chintinne M, Larsimont D, Nogaret JM, Veys I., 2020. A radical approach to achieve complete cytoreductive surgery improves survival of patients with advanced ovarian cancer. J Visc Surgery, 157(2), pp.79-86.

17. Falconer, H., Joneborg, U., Krawiec, K., Palsdottir, K., Bottai, M. and Salehi, S., 2020. Ultra-radical upfront surgery does not improve survival in women with advanced epithelial ovarian cancer; a natural experiment in a complete population. Gynecologic Oncology, 159(1), pp.58-65.

18. Hall, M., Savvatis, K., Nixon, K., Kyrgiou, M., Hariharan, K., Padwick, M., Owens, O., Cunnea, P., Campbell, J., Farthing, A., Stumpfle, R., Vazquez, I., Watson, N., Krell, J., Gabra, H., Rustin, G. and Fotopoulou, C., 2022. Maximal-Effort Cytoreductive Surgery for Ovarian Cancer Patients with a High Tumor Burden: Variations in Practice and Impact on Outcome. 
19. Yalcin, Y., Tatar, B. \& Erdemoglu, E., 2019, The parameters to estimate postoperative severe complications classified through Clavien-Dindo after upper abdominal surgery in patients with primary and recurrent ovarian cancer. Ginekologia polska.

20. Xu, Z. et al., 2020. Complications and survivorship trends after primary debulking surgery for ovarian cancer. Journal of Surgical Research, 246, pp.34-41.

21. Baldewpersad Tewarie, N.M.S. et al., 2021. Postoperative outcomes of primary and interval cytoreductive surgery for advanced ovarian cancer registered in the Dutch Gynecological Oncology Audit (DGOA). Gynecologic Oncology, 162(2), pp.331-338.

22. Dottino, J.A. et al., 2020. National trends in bowel and upper abdominal procedures in ovarian cancer surgery. International Journal of Gynecologic Cancer, 30(8), pp.1195-1202.

\section{Figures}

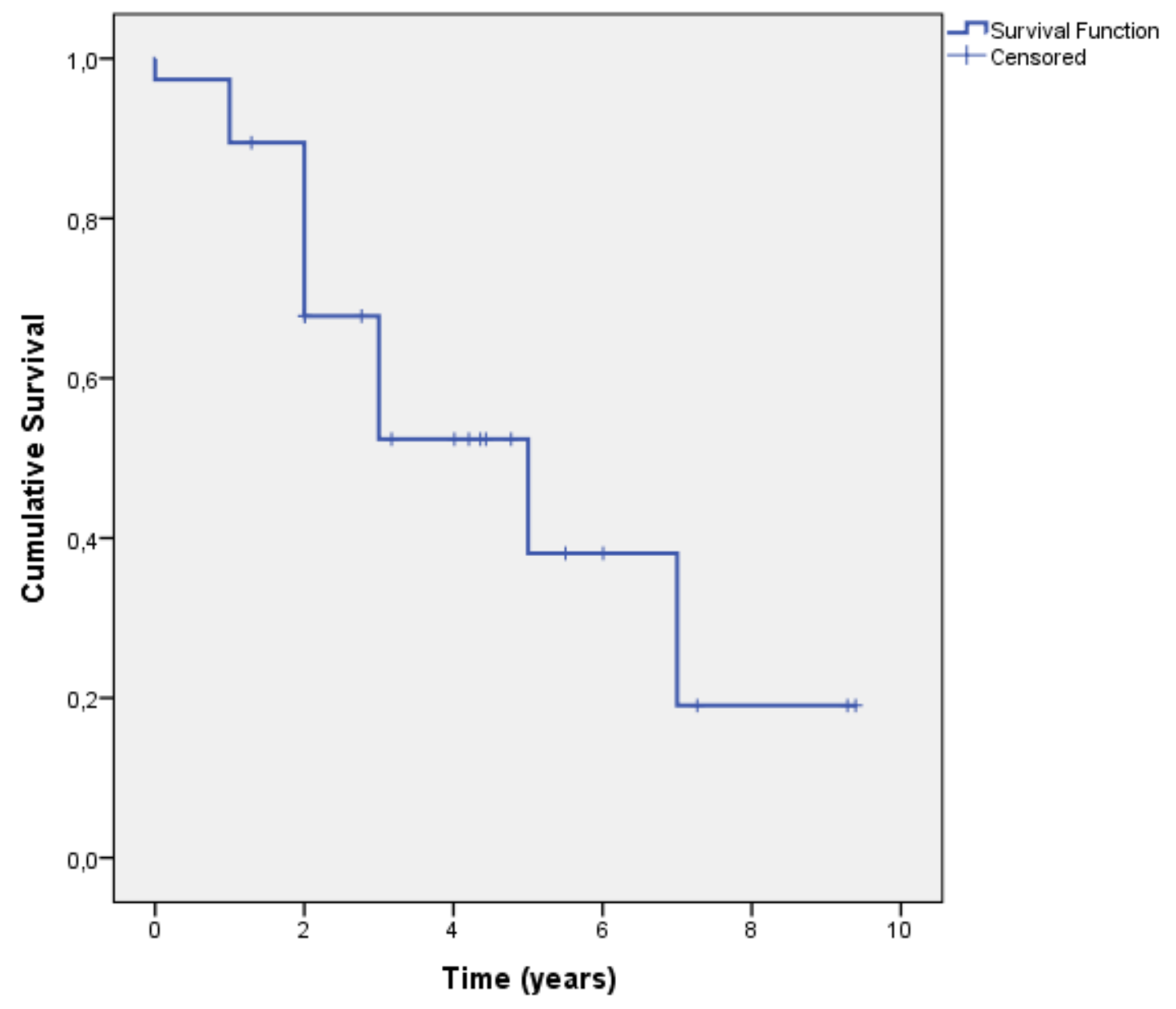

\section{Figure 1}

Kaplan-Meier curve for overall survival 


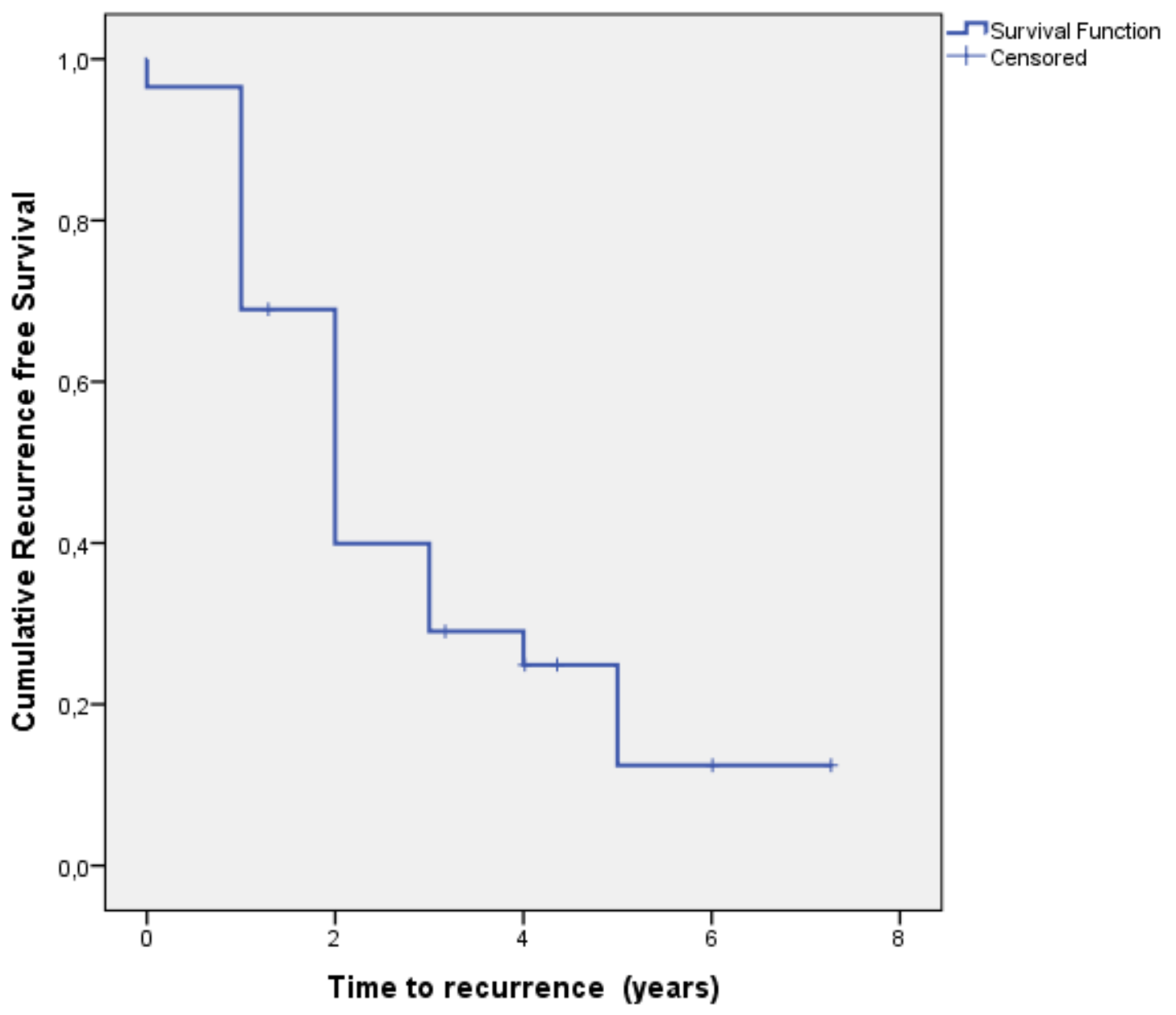

Figure 2

Kaplan-Meier curve for recurrence free survival 


\begin{tabular}{|c|c|c|c|}
\hline \multicolumn{4}{|c|}{ Perioperative Complications } \\
\hline Major (3-5) & $\begin{array}{l}\text { Number } \\
\text { of } \\
\text { Patients }\end{array}$ & Minor (1-2) & $\begin{array}{l}\text { Number } \\
\text { of } \\
\text { Patients }\end{array}$ \\
\hline $\begin{array}{l}\text { Pneumothorax - } \\
\text { intubation }\end{array}$ & 1 & $\begin{array}{l}\text { Allergic Reaction to } \\
\text { medication - transient } \\
\text { tachycardia }\end{array}$ & 1 \\
\hline $\begin{array}{l}\text { Intra-abdominal } \\
\text { collection (Drainage by } \\
\text { Interventional } \\
\text { Radiology) }\end{array}$ & 2 & Paralytic Ileus & 3 \\
\hline $\begin{array}{l}\text { Superficial Wound } \\
\text { dehiscence (Return to } \\
\text { theatre) }\end{array}$ & 3 & $\begin{array}{l}\text { Lower Respiratory } \\
\text { Tract Infection }\end{array}$ & 5 \\
\hline \multirow{12}{*}{$\begin{array}{l}\text { Exploratory Laparotomy } \\
+ \text { Washout }\end{array}$} & 1 & Blood Transfusion & 6 \\
\hline & & Electrolyte Imbalance & 6 \\
\hline & & $\begin{array}{l}\text { Coagulation } \\
\text { abnormality }\end{array}$ & 1 \\
\hline & & Sciatica & 1 \\
\hline & & Pulmonary Embolism & 5 \\
\hline & & High output stoma & 1 \\
\hline & & $\begin{array}{l}\text { Total Parenteral } \\
\text { Nutrition }\end{array}$ & 2 \\
\hline & & $\begin{array}{l}\text { Hospital Acquired } \\
\text { Pneumonia }\end{array}$ & 3 \\
\hline & & Pyelonephritis & 1 \\
\hline & & Acute Kidney Failure & 1 \\
\hline & & Atrial Fibrillation & 1 \\
\hline & & $\begin{array}{l}\text { Apical Pneumothorax } \\
\text { (conservative } \\
\text { management) }\end{array}$ & 1 \\
\hline
\end{tabular}

\section{Figure 3}

Complications 